\title{
A Pessoa com Deficiência no Mercado de Trabalho e suas Implicações
}

\author{
Melissa Campello Guedes dos Anjos ${ }^{1}$; Schamkypou Bernardo Bezerra ${ }^{2}$; Athena de Albuquerque Farias ${ }^{3}$; \\ Gisanne de Oliveira Marinho ${ }^{4}$; Julyanne de Oliveira Paes Barreto 5
}

\begin{abstract}
Resumo: O estudo teve o bjetivo de analisar a inclusão da pessoa com deficiência no mercado trabalho. Para isso, utiliza como base, a lei 8.213/9; em que observa-se sua real aplicabilidade, como também seu alcance e efeitos, no que diz respeito à parcela de pessoas que se destina atender. Seu desenvolvimento se perfaz através do embasamento teórico, por meio de pesquisas bibliográficas; e prático, com aplicação de pesquisa de campo. Verifica-se, através de dados colhidos, que o referido diploma legal não atinge, de forma plena, os objetivos aos quais se destina. Seja em razão da discriminação presente na sociedade, da dificuldade de locomoção, da baixa escolaridade, ou até mesmo em relação à efetividade da Lei de Cotas. Busca-se, dessa maneira, um caminho para se chegar a um mercado de trabalho mais inclusivo e uma sociedade mais consciente e compreensiva, para lidar e conviver com as diferenças.
\end{abstract}

Palavras-chave: Pessoas com deficiência. Mercado de trabalho. Inclusão. Discriminação. Lei de Cotas.

\section{The Person with Disabilities in the Labour Market And Its Implications}

\begin{abstract}
This work is a study in order to examine the inclusion of persons with disabilities in the labor market. For this, it uses as a base the Law 8.213 / 9; where they observe their actual applicability, as well as its scope and effects as regards the portion of people it is intended answer. Its development makes up through the theoretical foundation, through literature searches; and practical, with application of field research. It is found through data collected for that legal diploma does not reach full strength of the objectives to which it is intended. Either because of discrimination present in society; the limited mobility; the low education, or even compared the effectiveness of the Quota Law. Search up this way, one way to achieve a more inclusive labor market and a more conscious society and understanding to deal and live with differences.
\end{abstract}

Keywords: People with disabilities. Labor market. Inclusion. Discrimination. Quota law.

\section{Introdução}

O presente trabalho analisa uma temática de grande relevância para toda sociedade, no que diz respeito à inclusão da pessoa com deficiência em todos os setores da sociedade. Percebe-se que, com os grandes avanços da sociedade moderna, o sentimento de exclusão, como também as atitudes discriminatórias que outrora ocorriam, passaram a ser expurgadas pelo nosso ordenamento jurídico.

\footnotetext{
${ }^{1}$ Advogada pela Faculdade dos Guararapes, PE. E-mail: melissa_campello@ hotmail.com;

${ }^{2}$ Advogada trabalhista. Mestre em direito do trabalho pela UFPE e Especialista em direito do trabalho. Professora de direito do trabalho e processo do trabalho na Faculdade dos Guararapes, PE. E-mail: schamky@ gmail.com;

${ }_{3}^{3}$ Advogada pela Faculdade dos Guararapes, PE. Autor correspondente - Email: athena.farias@gmail.com;

${ }^{4}$ Advogada pela Universidade Federal Fluminense (UFF), RJ. Email: gihmarinho@ gmail.com;

5 Acadêmica de Direito pela Faculdade Metropolitana, PE.E-mail:july_paes2@ hotmail.com.
} 
Tal perspectiva leva as autoridades a se voltarem para elaboração de políticas e leis direcionadas à construção de uma sociedade mais inclusiva.

Entretanto, analisaremos, no corpo desta monografia, especificamente, a inclusão da pessoa com deficiência no mercado de trabalho, analisando dados como: a importância da lei 8.213/91 (Lei de cotas), uma vez que esse instrumento legal visa garantir uma maior participação desse grupo nesse setor.

Outro aspecto relevante sobre essa temática se traduz no fato de que, para se ter uma integração na atividade laboral, a problemática da inclusão vai muito além da pouca aplicabilidade ou ineficácia da referida lei. Como, por exemplo, oferecer meios ao trabalhador que possui algum tipo de deficiência para exercer, de forma digna, ou ainda desmitificar os sentimentos preconceituoso ou atitudes discriminatórias que ainda estão arraigadas não só em relação ao empregador, mas também no que diz respeito a toda sociedade.

Para aprofundarmos o nosso tema, dividiremos a monografia em quatro capítulos. No primeiro capítulo apresentaremos um breve histórico da pessoa com deficiência, seguindo de sua conceituação, de acordo com a convenção dos direitos do indivíduo que possui alguma deficiência. No seu decorrer, falaremos sobre as dificuldades enfrentadas por esses indivíduos para atuar seu mercado de trabalho.

No segundo capítulo nos debruçaremos sobre o fenômeno da discriminação, presente nas várias dimensões sociais, apesar da sua vedação no nosso ordenamento.

Dando continuidade ao tema, no terceiro capítulo, abordaremos de maneira específica os diversos sistemas da Lei cotas existentes, bem como alguns aspectos relevantes sobre a Lei de cotas.

No quarto e último capitulo, analisaremos os dados da pesquisa de campo por meio de um questionário aplicado às pessoas com deficiência já inseridas no mercado de trabalho, como àquelas que pretendem entrar. Concluiremos esse capítulo com uma apreciação crítica da temática.

\section{A Pessoa com Deficiência e sua Inserção na Sociedade: Um Breve Histórico}

Nas civilizações mais antigas os indivíduos que detinham algum tipo de deficiência eram esquecidos ou abandonados, por acreditarem que eles possuíam alguns espíritos maus, em suma, eram tidos como impuros. No entanto, foi a partir da Revolução Industrial que a pessoa com deficiência passou a ser compreendida como alguém capaz de exercer um papel na sociedade, utilizando sua força de trabalho. Como afirma Miranda: 
Isto só ocorreu porque o contexto social, cultural e político deste dado momento histórico estava favorável, no sentido de necessitar que as pessoas com deficiência aproveitassem seu potencial produtivo. (MIRANDA, 2003)

Com o surgimento das grandes guerras, onde muitos indivíduos foram seriamente mutilados física e psicologicamente, a sociedade passa a conviver com uma nova realidade: um grande número de pessoas mutiladas, que passam a serem consideradas deficientes. Tal realidade conduziu a sociedade a uma reflexão sobre a situação deles, que não conseguiam exercer suas atividades laborais como outrora. Essa reflexão esta conduz a sociedade a intensificar o processo de inclusão, aflorando, então, um sentimento humanístico, em populaçqueão começa a ter consciência de que a sociedade deve se adequar a todos. Como afirma Miranda:

Todo este contexto causou um impacto na sociedade, que passou a buscar alternativas para resolver estas questões advindas da guerra. Se antes a sociedade não se preocupava com a questão da pessoa com deficiência, após este período tal questão ficou muito mais próxima. Afinal, o contingente de pessoas que foram acometidas por lesões, as mais variadas possíveis, causando uma série de deficiências, aumentou muito neste momento histórico. (MIRANDA, 2003)

A promulgação da nossa Carta Magna de 1988 facilitou e ainda vem desenvolvendo esse processo inclusivo, por abarcar, em seu bojo, artigos, incisos e capítulos, voltados para angariar tal fim. Contudo vale ressaltar que eles nem sempre possibilitam a tão sonhada eficácia plena.

Porém ainda há muitos obstáculos a serem vencidos, almejando assim, uma maior participação social, a fim de que direitos e deveres dessa minoria sejam assegurados.

\section{Trabalho e Desenvolvimento Social}

O trabalho corresponde a uma atividade de extrema importância para os indivíduos da sociedade, além disso garante o desenvolvimento pessoal, melhorando a auto estima como também contribui para a formação do caráter de cada um, independente de possuir ou não algum tipo de deficiência. Em Pardim:

A linguagem, os hábitos cotidianos, os comportamentos, os significados das coisas sempre foram mediados pela cultura e o trabalho não escapa desta mediação uma vez que ele é parte importante da construção da identidade do indivíduo e do seu desenvolvimento pessoal, não importando a condição de pessoa, com ou sem deficiência, ou seja, o trabalho se torna indispensável para a inclusão social. (PARDIM, 2014, p. 02) 
Podemos ir mais além, ao considerar que o trabalho como a força motriz que impulsiona a vida de todos indivíduos, pois, é através dessa atividade que começamos a garantir nosso sustento, construímos uma família e nos esforçamos a estar sempre buscando uma qualificação para se manter no mercado. Enfim estaremos exercendo nossa cidadania. Vale ressaltar que a situaçã, em comento ocorre com todos os indivíduos, independente de possuir ou não alguma deficiência. Como esclarece Pardim:

O trabalho é atividade pela qual se exerce a cidadania, fazemos cumprir nossos direitos, ganhamos nosso sustento para podermos constituir uma nova família. E assim o é para a pessoa com deficiência, sem trabalho, não há perspectiva de crescimento, não há motivação para o estudo e o aperfeiçoamento. Nós mesmos, muitas vezes pensamos: como sobreviver sem trabalho? Trabalho é muito mais do que emprego e sustento, é o caminho para uma vida de respeito e esperança. (PARDIM, 2014, p. 10)

Porém, para que tal situação torne-se realidade, faz-se mister desenvolver, de maneira eficaz e ética, o combate à discriminação e às práticas preconceituosas. E, um momento seguinte, dentro de um processo educativo, preparar as pessoas no ambiente de trabalho para que compreendam as necessidades especiais existentes em cada um. E, a partir de tal processo, recebam o colega com deficiência com a merecida dignidade e respeito, não o vendo como um ser incapaz, mas como mais um profissional para contribuir com desenvolvimento da empresa. Como bem enfatiza Ford:

As pessoas que irão ter a pessoa com deficiência como colegas de trabalho devem ser preparadas para recebê-lo e tratá-lo com respeito. Todos na empresa devem ver o deficiente como colega de trabalho como os outros, é claro que com algumas necessidades especiais, mas não menos capaz. Isso deve partir, principalmente, de quem contrata, pois contratar o deficiente por caridade, ou apenas para cumprir uma legislação ou uma determinação é dar margem para o preconceito. O empregador também deve ver o deficiente como um funcionário que, estando em condições, pode render tanto quanto os outros, ou até mais. (FORD apud PARDIM, 2014, p. 10)

No entanto, ao tratamos especificamente da celeuma, no que diz respeito à inclusão da pessoa com deficiência, verificamos que tal problemática vai muito além da atitude discriminatória do empregado; temos, a pouca eficácia da Lei de cotas, assunto do qual falaremos mais tarde; ou ainda, o processo de deslocamento para chegar ao local de trabalho é bastante complicado, seja em razão das barreiras arquitetônicas presentes nas cidades, como por exemplo os meios de transporte público acessível com um contingente inferior para atender a demanda desta parcela da sociedade. Como relata Fernandes e Silva:

O papel do governo no processo de inclusão da pessoa com deficiência no mundo do trabalho. Ao propor uma sociedade inclusiva, em que todas as pessoas tenham a oportunidade de participar, o próprio governo não consegue cumprir a sua parte. Há falhas na educação, na saúde, nos meios de transporte, nas ruas e nas calçadas entre 
outros, que dificultam e até impedem a participação da pessoa com deficiência no mercado do trabalho. (FERNANDES e SILVA, 2008, p. 21)

\section{Conceito da Pessoa com Deficiência}

O processo que considerava o indivíduo deficiente era tido como extremamente subjetivo, pois apenas analisava se determinada pessoa estava inserida nos critérios médicos do que era ser considerado deficiente, ou seja, essa realidade denotava, unicamente, uma problemática voltada para o âmbito da saúde.

Entretanto, com a realização da Convenção Sobre os Direitos da Pessoa com Deficiência, patrocinada pela Organização das Nações Unidas - ONU - em agosto de 2008, como também o do Decreto Legislativo $\mathrm{n}^{\circ} 186$, de 09 de julho de 2008, foram fatores primordiais para que houvesse a ampliação do conceito da pessoa com deficiência. Uma vez que era necessário que a referida expressão acompanhasse os avanços sociais adquiridos por esta parcela da população, de maneira a acrescentar um cunho social. Como podemos observar em seu preâmbulo, na alínea "e":

Reconhecendo que a deficiência é um conceito em evolução e que a deficiência resulta da interação entre pessoas com deficiência e as barreiras devidas às atitudes e ao ambiente que impedem a plena e efetiva participação dessas pessoas na sociedade em igualdade de oportunidades com as demais pessoas. (ONU, 2008)

Tal convenção continha em seu bojo, entre tantos outros aspectos, o reconhecimento da diversidade das deficiências existentes, admitindo desta forma, que cada espécie possuísse, assim, um tratamento especifico, de acordo com as peculiaridades apresentadas por cada indivíduo.

O objetivo dessa conferência foi muito mais além do que apenas ampliar o conceito de deficiência, garantindo um âmbito de proteção e inclusão para aquele grupo, como também asseverando para a sociedade que, embora o indivíduo possua algum tipo de deficiência, ele poderá, na maioria das vezes, produzir, de maneira a exercer um papel social. De acordo com seu artigo 1:

O propósito da presente Convenção é promover, proteger e assegurar o exercício pleno e equitativo de todos os direitos humanos e liberdades fundamentais por todas as pessoas com deficiência e promover o respeito pela sua dignidade inerente. Pessoas com deficiência são aquelas que têm impedimentos de longo prazo de natureza física, mental, intelectual ou sensorial, os quais, em interação com diversas barreiras, podem obstruir sua participação plena e efetiva na sociedade em igualdade de condições com as demais pessoas. (ONU, 2008)

Depois de tentarmos demostrar como o conceito da pessoa com deficiência foi evoluindo ao longo tempo, onde a realização da convenção que versava sobre os direitos das pessoas com 
deficiência em meados de 2008 teve um papel fundamental para tal avanço, passaremos a abordar um tema de total relevância para o corpo deste trabalho é a inclusão da pessoa com deficiência no âmbito laboral.

\section{Pessoas com Deficiência e Acesso à Educação de Qualidade}

Outro fator primordial para possibilitar a participação desse grupo no mercado de trabalho é a educação de qualidade, que faz com que as pessoas nela inseridas obtenham, futuramente, um papel social, gerando assim uma maior inclusão. Esse direito está previsto expressamente na nossa lei maior, como também em outros diplomas legais que vão mais além, discorrendo sobre uma educação inclusiva. Como observa Pardim:

Para ingressar no mercado de trabalho, é preciso que a pessoa com deficiência, como qualquer outra pessoa, tenha o acesso a uma educação de qualidade e que possibilite a elas condições para tal. A Constituição determina que o direito à educação das pessoas com deficiência deve ser garantido pelo Estado por meio de um atendimento educacional especializado, de preferência na rede regular de ensino, conforme define o artigo 208, inciso III, da Constituição Federal. Além da constituição, o direito à educação a pessoa com deficiência, é mencionado também em leis federais, estaduais e em todas as leis municipais do país. (PARDIM, 2014, p. 17)

Entretanto nem todas as pessoas com deficiência têm acesso a esse direito fundamental, imprescindível para sua qualificação e, consequentemente, ascensão profissional. Por outro lado, quando determinado indivíduo tem acesso a tal direito, nem sempre apresenta uma qualificação satisfatória exigida pelo mercado. Isto ocorre por alguns motivos relevantes, como por exemplo, a problemática em torno da má estruturação física e pedagógica das nossas escolas, como também o sentimento de super proteção dos familiares. Conforme nos apresenta o artigo da Organização Internacional do Trabalho:

O acesso ao mercado de trabalho representa para a pessoa com deficiência uma forma de incluir-se na sociedade, abrindo-lhes espaços de participação social e de exercício pleno da cidadania. As pessoas com deficiência também não foram dadas iguais oportunidades de acesso à escolarização. Entretanto, muitas vezes, apesar de não terem a certificação, tiveram acesso ao conhecimento por meio do apoio da família ou da comunidade local. De outro lado, muitas vezes é exigido, de forma generalizada, um patamar de escolaridade que não é compatível com exigências de fato necessárias para o exercício das funções. Assim sendo, revelar suas reais condições de realizar o trabalho. (OIT, ART. 36, alínea "c", da Recomendação n ${ }^{\circ}$ 168) 


\title{
Mercado de Trabalho: qualificação, limites e desafios
}

Outra consequência do fato da realidade acima citada tem, como resultado, uma significativa deserção escola,r tendo como predominância, em tal público, uma baixa escolaridade, como ilustra a pesquisa "Retratos da Deficiência no Brasil", da Fundação do Banco do Brasil e da Fundação Getúlio Vargas:

\begin{abstract}
A escolaridade média das pessoas portadoras de deficiência é de 3,95 anos de estudo, isto é, quase um ano inferior do que a média da população brasileira... são mais excluídas de atributos educacionais e digitais... vivem abaixo da linha de miséria 29,055\% das PPDs (Pessoas Portadoras de Deficiências) os afrodescendentes possuem $9 \%$ e $3 \%$ a mais de chances de possuírem deficiência... a renda média do trabalho das pessoas com deficiência é inferior a das pessoas sem deficiência. (NERI, 2003, p. 28)
\end{abstract}

Por lado, quando determinada pessoa com deficiência obtém a qualificação necessária exigida pela nossa sociedade capitalista, tendo com isso a oportunidade de ingressar no mercado de trabalho, conquistando, paulatinamente, a tão sonhada independência pessoal e financeira, ela ainda deverá enfrentar inúmeros desafios, de forma a exercer sua função dentro da empresa com plena eficácia como, por exemplo, demonstrar para o empregador que, apesar de possuir algum tipo de deficiência, tem capacidade para assumir determinado cargo ou função.

Para amenizar os desafios enfrentados por essa parcela da população, o governo vem fortalecendo parcerias junto aos órgãos públicos, visando à implementação de políticas públicas, com o intuito de facilitar a efetiva inclusão da pessoa com necessidades especiais no âmbito laboral. Como explica Vash:

Entre as razões que fazem com que o empresário não contrate a pessoa com deficiência está o preconceito, ou seja, uma dificuldade em acreditar que esta pessoa possa ser bem sucedida e exercer seu trabalho com sucesso. O desenvolvimento de ações permanentes junto aos órgãos públicos e legisladores se fazem necessários para garantir a atenção e a proteção aos direitos das pessoas com deficiência. (VASH, 1988, p.07)

Um fundamental mecanismo usado para facilitar a participação dos indivíduos que fazem parte das chamadas "minorias' na esfera trabalhista é o denominado sistema de cotas ou reserva legal que se perfaz mediante políticas públicas, ou as chamadas ações afirmativas, às quais trataremos de forma mais detalhada, posteriormente em um capítulo específico. Por ora ficaremos apenas com o conceito ensinado por Lopes,

O sistema de reservas legal de vagas ou sistemas de cotas é um mecanismo compensatório utilizado para a inserção de terminados grupos sociais, facilitando o exercício dos direitos ao trabalho, à educação, à saúde, ao esporte etc. É uma forma 
de ação afirmativa com o intuito de tentar promover a igualdade e o equilíbrio de oportunidades entre os diversos grupos sociais. (LOPES, 2005, p. 93)

Outro aspecto de total relevância para o referido tema abordado neste capítulo diz respeito à atuação do Ministério Público do Trabalho, quando nos referimos à inclusão da pessoa com deficiência no âmbito laboral. Assunto este, que tentaremos discorrer a seguir.

\section{Ministério Público e Inclusão no Âmbito Laboral}

O Ministério Público do Trabalho é um órgão que exerce um papel fundamental na missão de tornar o mercado de trabalho cada vez mais inclusivo, de maneira a fiscalizar se determinado percentual estipulado pela Lei de cotas está sendo cumprido pelas empresas. Procuraremos demonstrar de forma sucinta como as etapas do procedimento realizado pelo ministério público tem como principal objetivo facilitar a inclusão da pessoa com deficiência no mercado de trabalho.

Inicialmente vale ressaltar que essa atuação do Ministério Público, na maioria das vezes, possui um aspecto mais conciliatório que repressivo. Primeiramente, tal órgão colhe dados referentes ao número de empregados de uma determinada empresa, verificando destarte se o referido quadro de funcionários está obedecendo o percentual da reserva legal estipulado pelo diploma denominado Lei de cotas. Por outro lado, havendo uma negativa dessas informações, será realizada uma fase de conciliação, presidida pelo procurador do trabalho, no intuito de solucionar o conflito.

No entanto, se esse objetivo não for alcançado, a empresa assinará um termo de ajustamento de conduta - TAC, que conterá um prazo para o cumprimento da obrigação, gerando, gradativamente, a contratação daquele público. Contudo ainda há a possibilidade de a empresa recusar a assinatura do documento. Dessa forma o Ministério Público, no exercício de sua função, ajuizará uma ação civil pública para que tal empresa se posicione ao referido comportamento. Caso este feito seja julgado procedente, o mesmo estabelecimento estará, de maneira coercitiva, obrigado a realizar novas contratações sob pena de multa. A partir da lei 8213/91(Lei de cotas), houve a possibilidade da decretação de multas, em razão do descumprimento legal. Podemos observar que, no procedimento anterior ao referido diploma legal, o Ministério Público apenas instaurava inquéritos civis, pois ainda não existia a fase conciliatória acima referida. Como esclarece Lopes:

A lei $\mathrm{n}^{\circ} 8.213 / 91$ e o decreto $\mathrm{n}^{\circ} 3.298 / 99$ trataram da reserva de vagas para portadores de deficiência, mas não previram a imposição de multas às empresas que descumprem a cota. Até outubro/2003, a forma eficaz de forçar as empresas a observarem a lei era a instauração de inquéritos civis e propositura de ações civis públicas pelo Ministério Público do Trabalho. (LOPES, 2005, p. 107) 


\section{Ministério Público e Parceiros na Luta pela Inclusão}

Depois de observamos, brevemente, o processo do Ministério Público do Trabalho, trataremos de algumas entidades que, em parceria com o MPT, favorecem para que o mercado de trabalho seja cada vez mais inclusivo. O Instituto Nacional do Seguro Social influencia bastante na aplicação da Lei de cotas, principalmente no que diz respeito aos assegurados reabilitados, tendo em vista que o referido órgão mantém para estes um banco de dados. Em seguida o referido órgão fornece às empresas que adotam o sistema de reservas de cotas, possibilitando-lhes uma oportunidade no mercado. É também papel do INSS encaminhar ao Ministério Público do Trabalho as empresas que infringem a lei.

Não podemos deixar de citar o importante papel realizado pelo Instituto Brasileiro de Defesa dos Direitos da Pessoa Portadora de Deficiência - IBDD -, haja vista o fornecimento de um suporte de consultoria, analisando, dentro de cada empresa, a necessidade de tornar aquele âmbito empresarial apto para receber os indivíduos que possuem algum tipo de deficiência, como demonstra Lopes:

Por intermédio do trabalho de consultoria, dá suporte às empresas com a análise de suas necessidades, inclusive, arquitetônicas, verificação da compatibilidade de cargos e tipo de deficiências, oferecimento de palestra educativas e cursos de aperfeiçoamento, acompanhamento e integração dos empregados selecionados. Tem atuação conjunta com o Ministério do Trabalho e Emprego, por meio da Delegacia Regional do Trabalho. (LOPES, 2005, p.108)

Ademais todo esse processo de parceria entre o Ministério Público do Trabalho e os referidos órgãos governamentais só terão grandes efeitos, havendo, de imediato, um processo de conscientização das empresas e da sociedade como um todo, através de campanhas educativas, demostrando a capacidade daquele grupo executar com êxito suas funções. Gerando desta forma uma integração com todos os membros das empresas.

\section{Políticas de Cotas para o Mercado de Trabalho da Pessoa com Deficiência}

Neste capítulo iremos nos debruçar sobre a lei 8.213/91(Lei de Cotas), de fundamental importância para a inclusão da pessoa com deficiência no mercado de trabalho. Como vimos no capítulo anterior, o sistema de cotas, segundo Lopes, é um mecanismo compensatório, utilizado para inclusão de determinados grupos, com o intuito de facilitar a igualdade de oportunidades em diversas áreas existentes na sociedade. 
O referido tema começou a surgir logo após a primeira grande guerra, tendo em vista o grande número de ex-combatentes que acarretava uma sobrecarga no âmbito da previdência social. Tal posicionamento aos poucos foi sendo aceito pela Organização internacional do Trabalho - OIT. Como bem fundamenta Lopes:

Historicamente, o sistema de cota empregatícias apareceu na Europa, no início do século XX, como forma de acomodação dos ex-combatentes mutilados na Grande Primeira Guerra, que vinham sobrecarregando a previdência social dos países nela envolvidos.

Em 1923, a Organização internacional do Trabalho - OIT, recomendou a aprovação de leis nacionais que obrigavam entidades públicas e privadas a empregar certo número de ex-combatentes portadores de deficiência. Em 1944, essa Recomendação da OIT foi estendidas aos demais portadores de deficiência. Aos poucos vários países adotaram o sistema de cotas. (LOPES, 2005, p. 93)

\section{Diversas Modalidades da Lei de Cotas}

Existe outro sistema que também versa sobre a política de cotas é o denominado sistema de cotas-contribuição, que tem como principal intuito favorecer para formação de fundo público destinado a reabilitação dos mutilados, quando não é possível empregá-los no mercado de trabalho. Vale ressaltar que alguns países adotam simultaneamente os dois sistemas, qual seja: o sistema de cotas propriamente dito, onde a lei estipula um percentual obrigatório de vagas em seu quadro de funcionários, na empresa, destinadas ao público que possui algum tipo de deficiência. O segundo é o sistema de cota-contribuição, já reportado alhures. Porém críticos ao segundo sistema, alegam que o pagamento de valor como forma de liberar a contratação é um meio de discriminar, não gerando a função inclusiva ao que o sistema se destina. Como observa Pastore:

Os críticos do sistema cota-contribuição entendem que o pagamento de um valor como forma de se liberar de contratação nada mais é para legitimamente discriminar. Acrescentam, ainda, que o pagamento não atende a função de integração das pessoas portadoras de deficiência ao ambiente normal de trabalho, como falam as normas da OIT. (PASTORE in LOPES, 2000, p. 94)

\section{A Lei de Cotas no Âmbito Constitucional}

Depois de analisarmos alguns modelos referentes às cotas, adotados por alguns países como Alemanha, Áustria, França, Itália entre outros, que tem como principal intuito facilitar a inclusão da pessoa com deficiência no mercado de trabalho formal, discorreremos, de plano, o modelo adotado pelo ordenamento jurídico pátrio. 
A nossa Constituição, ora vigente, já abarcava no bojo de seu artigo 37, VIII, o mecanismo de inclusão das pessoas com deficiência no âmbito laboral, especificamente, no que concerne ao setor público. Gerado conjuntamente com as ações afirmativas, como versa o referido artigo:

Art. 37. A administração pública direta e indireta de qualquer dos Poderes da União, dos Estados, do Distrito Federal e dos Municípios obedecerá aos princípios de legalidade, impessoalidade, moralidade, publicidade e eficiência e, também, ao seguinte:

VIII - a lei reservará percentual dos cargos e empregos públicos para as pessoas portadoras de deficiência e definirá os critérios de sua admissão;

Porém, com o surgimento da lei 8.213/91, houve a preocupação do legislador em ampliar tal direito para o setor privado, desenvolvendo, por exemplo, o conceito da pessoa com deficiência apta para exercer uma função no mercado. Como também em seu artigo 93 que versa sobre o percentual no que se refere à reserva de vagas para esta parcela da população. Como demonstra Costa:

Todavia, as disposições do art. 93 da Lei 8.213/91 foram repetidas no Decreto 3.298/99, sendo que este introduziu algumas disposições adicionais referente ao conceito de pessoa portadora de deficiência habilitada e também quanto à competência do Ministério do Trabalho e Emprego para estabelecer uma sistemática de fiscalização, avaliação e controle das empresas, com vistas a propiciar estatísticas sobre o número de empregados portadores de deficiência. (COSTA, 2011, p.22)

\section{Considerações sobre o Artigo 93 da Lei 8.213/91}

O artigo 93 da referida lei é de suma importância, pois apresenta, entre outros aspectos, o percentual que deve ser obedecido nas empresas que apresentam um quadro de funcionários com um efetivo a partir de cem pessoas. Como verificamos no artigo 93, in verbis:

Art. 93. A empresa com 100 (cem) ou mais empregados está obrigada a preencher de $2 \%$ (dois por cento) a $5 \%$ (cinco por cento) dos seus cargos com beneficiários reabilitados ou pessoas portadoras de deficiência, habilitadas, na seguinte proporção: I - até 200 empregados ...................2\%

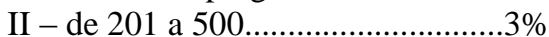

III - de 501 a $1.000 \ldots \ldots \ldots \ldots \ldots \ldots \ldots \ldots \ldots . . .4 \%$

IV - 1.001 em diante..........................5\%

$\S 1^{\circ}$ A dispensa de trabalhador reabilitado ou de deficiente habilitado ao final de contrato por prazo determinado de mais de 90 (noventa) dias, e a imotivada, no contrato por prazo indeterminado, só poderá ocorrer após a contratação de substituto de condição semelhante.

$\S 2^{\circ} \mathrm{O}$ Ministério do Trabalho e da Previdência Social deverá gerar estatísticas sobre o total de empregados e as vagas preenchidas por reabilitados e deficientes habilitados, fornecendo-as, quando solicitadas, aos sindicatos ou entidades representativas dos empregados. 
Um aspecto importante a ser considerado é o dever do empregador de verificar se determinada pessoa com deficiência está qualificada e habilitada para o eficaz preenchimento da vaga. Efetivando, desta forma, a atividade laboral com eficiência. Conforme Madeiro:

Desta feita, o deficiente, muitas vezes por força de sua incapacidade em executar determinadas funções do dia a dia, não consegue chegar ao nível almejado pela maioria das empresas, permanecendo à margem do mercado de trabalho. Tal dificuldade, muito embora se dê por questões fisiológicas, na maioria das vezes, pode ser dirimida, através de treinamentos específicos que visem à qualificação desse público. (MADEIRO, 2014, p. 09)

Para que tenhamos uma melhor e mais detalhada compreensão no que se refere ao termo deficiente habilitado, se faz mister nos debruçarmos nas definições existentes no decreto 3.298/99:

Igualmente, são consideradas pessoas portadoras de deficiência habilitadas, de acordo com o Decreto 3.298/99, aquelas que concluíram curso de educação profissional de nível básico, técnico ou tecnológico, ou curso superior, com certificação ou diplomação expedida por instituição pública ou privada, legalmente credenciada pelo Ministério da Educação ou órgão equivalente, ou aquela com certificado de conclusão de processo de habilitação ou reabilitação profissional fornecido pelo Instituto Nacional do Seguro Social (INSS), e também aquelas que, não tendo se submetido a processo de habilitação ou reabilitação, estejam capacitadas para o exercício da função.

Porém nem todos apresentam a qualificação exigida pelo mercado, seja em razão da falta de qualificação propriamente dita ou em decorrência de suas limitações físicas e fisiológicas. No entanto, para tentar solucionar esse impasse, o referido decreto, no intuito de proteger os direitos desse grupo, detém em seu bojo disposições legais visando oferecer assistência e cursos de qualificaçã, para os mesmos. Como podemos visualizar a seguir, in verbis:

Nesse sentido, segundo o Decreto, existem os seguintes elementos de assistência:

a) Apoio especial: são os serviços de orientação, supervisão e ajudas técnicas para facilitar a mobilidade e a utilização dos meios e recursos existentes no ambiente de trabalho.

b) Procedimentos especiais: são as providências a ser tomadas pelo empregador após a contratação para o trabalhador com deficiência que devido aos comprometimentos da deficiência exigem condições especiais, como jornada variável, horário flexível, proporcionalidade de vencimentos ou salário, ambiente de trabalho adaptado às suas especificidades, entre outros.

c) Ajudas Técnicas: são os elementos que permitem compensar uma ou mais limitações motoras, sensoriais ou mentais da pessoa com deficiência, com o objetivo de permitir-lhe superar as barreiras da comunicação e da mobilidade (pessoas ou cuidadores; produtos; instrumentos; equipamentos; animais).

No entanto vale ressaltar que muitas vezes o empregador opta por pagar as penalidades previstas na lei 8.213/91, por sua empresa está fora dos parâmetros exigidos pela referida Lei, tanto no 
que se refere ao quadro de funcionários, como adequar as possíveis instalações física minimizando as barreiras arquitetônicas, facilitando a inclusão de tal público no âmbito laboral. Como afirma Madeiro:

Em relação ao alto custo que a contratação de portadores de deficiência gera para o empregador, é valido mencionar que várias empresas preferem arcar com as multas aplicadas, a adaptarem-se às regras para a contratação dessa parcela significativa da sociedade, pois segundo alguns empresários simplesmente pagar a multa além de sair mais em conta gera menos transtorno. (MADEIRO, 2014, p. 10)

Continuando a análise do artigo 93, discorreremos mais especificamente sobre a hipótese estabelecida pelo referido diploma, através do §1, no que se refere à reintegração da pessoa com deficiência. Frisa-se que a pessoa que detém algum tipo de deficiência não possui estabilidade, no entanto ao ser dispensado, tal fato só poderá ocorrer de maneira efetiva quando for realizada nova contratação de seu substituto nas condições semelhantes. Como esclarece Costa:

Da leitura do $\S 1^{\circ}$ do artigo em análise extrai-se que o empregado portador de deficiência não possui estabilidade no emprego, eis que o empregador pode rescindir, a qualquer tempo, o contrato de trabalho. No entanto, o empregador tem como única limitação a contratação de outro profissional portador de deficiência, com o fim de preencher a cota prevista na lei. (COSTA, 2011, p.25)

\section{Local e Jornada de Trabalho da Pessoa com Deficiência}

Um aspecto fundamental para ser observado, diz respeito primeiramente ao local de trabalho em que a pessoa com deficiência irá exercer suas funções, tendo em vista que a maioria das empresas não apresentam condições que garantam a acessibilidade em sua estrutura física, facilitando assim uma maior desenvoltura no exercício de seu ofício profissional. Uma solução para amenizar essa situação é a possibilidade que tem o empregador de delegar atividades para que determinada pessoa a desenvolva no seu próprio domicílio.

Assim, com a finalidade de cumprimento do sistema de cotas previsto na legislação um dos primeiros obstáculos a ser eliminado diz respeito à eliminação de todas as barreiras arquitetônicas que impedem o acesso dos profissionais portadores de deficiência ao emprego.

Considerando que a eliminação de barreiras arquitetônicas demanda ações tanto do ente privado, contratante da pessoa portadora de deficiência, como das autoridades governamentais, fato é que a situação ideal ainda está longe de ser alcançada. Por esse motivo deve ser levada em consideração a possibilidade de a pessoa portadora de deficiência prestar serviços, como empregado celetista, no âmbito de sua residência, evitando-se o deslocamento trabalho-residência e vice-versa. (COSTA, 2014, p.32) 
Em relação à jornada de trabalho, no que diz respeito à pessoa com deficiência, a carga horária pode ser negociada com o empregador, podendo flexibilizar, por exemplo, reduzindo o total de horas semanais prestadas para determinada empresa de acordo com as peculiaridades de cada deficiência.

\section{Considerações Polêmicas sobre Lei 8.213/91}

Trataremos neste tópico de alguns aspectos polêmicos sobre a Lei de Cotas. Primeiramente comentaremos sobre o aspecto que a mesma lei deve incidir sempre de acordo com o número total de empregados em uma determinada empresa. Porém há estudiosos que acreditam que este percentual deveria coincidir não em relação ao percentual total de empregados, mas por estabelecimento, tendo em vista que várias empresas podem possuir várias sedes, colocando um número inferior ao exigido por ela. Desta maneira os empregadores ficam isentos para aplicação do artigo 93. Como fundamenta Costa:

Outra interpretação é feita por empresas que tem como objetivo o não cumprimento da lei. Estas empresas alegam que a aferição do cumprimento das cotas deve ser feita por estabelecimento e não sobre o total de empregados da empresa, eis que possuem mais de 100 empregados, mas tem uma série de estabelecimentos diferentes, nos quais a quantidade de empregados é inferior ao número estabelecido. Tem-se que o argumento sustentado por estas empresas deve ser afastado e elas devem ser autuadas para que cumpram a lei. (COSTA, 2014, p. 29)

Outro ponto a ser observado é que a leiI 8.213/91 não isenta as empresas que exercem atividades cujo labor pressupõe atividades perigosas e insalubres, a contratarem pessoas com deficiência. Por outro lado essa função não pode agravar a condição do empregado. De acordo com Costa:

Já as empresas que exercem atividades predominantemente insalubres ou perigosas, de acordo com os arts. 189 e 193 da CLT, em princípio, não existe qualquer impedimento para a contratação de empregados portadores de deficiência, não podendo ser presumida pelo empregador qualquer incompatibilidade entre a deficiência e o trabalho em local insalubre ou perigoso. Porém, a contratação não pode acarretar um agravamento na deficiência e nas eventuais dificuldades do empregado a ser contratado. (COSTA, 2014, p. 17) 


\section{Percepção sobre a discriminação e Inclusão no Mercado de Trabalho com Base na Pesquisa de Campo}

O objetivo do presente capítulo é apresentar e analisar dados coletados em uma pesquisa de campo realizada com pessoas que possuem algum tipo de deficiência e que já estão inseridas no mercado de trabalho. A finalidade é que, com tal aplicação, possamos observar na prática o alcance do que constatamos na teoria. A pesquisa foi realizada através da aplicação de um questionário com oito perguntas, disponibilizadas para dez pessoas, porém só seis pessoas apresentaram o resultado. Tais perguntas girou em torno de questões relevantes ao tema que esse trabalho monográfico se propõe.

Em seguida comentaremos sobre os dados que foram colhidos na referida pesquisa. Primeiramente, no que se refere ao questionamento sobre se estão ou não sentindo-se bem, e preparado para o mercado de trabalho.

- Todos, por unanimidade, declararam que em relação ao meio em que trabalham sentem-se desvalorizados, por não serem percebidos e tratados como pessoas capazes e profissionais, isto em razão de suas deficiências. Percebem, com facilidade, o olhar preconceituoso e discriminatório que faz presente no meio.

- No que se refere a sua preparação para atuar no mercado de trabalho, todos sentem-se preparados e qualificados para o exercício de sua profissão. Porém, no que se refere à visão das empresas, estas nem sempre percebe tal condição. Muitos empregadores os aceitam em seu quadro de funcionários apenas para eximir-se das penalidades impostas pelos diplomas legais.

- Em relação à Lei de Cotas, os participantes acham-na importante, por facilitar sua inserção do mercado de trabalho, tendo em vista que sem este mecanismo seria ainda mais difícil conquistar ter espaço. O que está intimamente ligado ao fato de que, infelizmente, a sociedade ainda tem uma visão estereotipada da pessoa com deficiência.

- Ao nos referirmos se a Lei de Cotas atende e respeita o deficiente como profissional, as respostas foram semelhantes. Foi geral que a Lei é ampla e possui muitas brechas. Não especifica nem detalha a exigência da contratação de profissionais com deficiência, e permite que a empresa dite as regras. Em processos seletivos as empresas dão prioridade para os candidatos que possuem leves sequelas.

- No que diz respeito à preparação do mercado de mercado de trabalho para receber a pessoa com deficiência, responderam que não. Isso porque os empregadores mantêm uma visão assistencialista e se preocupa mais em cumprir cotas, esquecendo de 
proporcionar uma oportunidade de crescimento e desenvolvimento profissional. Não existe, por parte de muitas empresas, uma consciência voltada para a adequação do ambiente de trabalho, tornando-o acessível, facilitando o cotidiano do deficiente, que com mais eficiência executará sua função.

- As respostas em relação à discriminação no mercado de trabalho, todos concordaram que existe e em muitas situações de maneira camuflada. Há empresas que procuram justificar situações discriminatórias com desculpas infundadas. Porém, cabe ao deficiente quebrar esse paradigma e desconstruir essa imagem de coitadinho, vítima da sociedade.

- Concluindo os dados da pesquisa com a pergunta sobre a visão do empregador em relação ao trabalhador que possui alguma deficiência, as respostas tiveram um mesmo fio condutor. Por isso, elegemos a resposta dada por W. M. A.: "ainda o visualizam como número, como percentual de cota, como coitado, alguém que se contenta com qualquer vaga. Pode parecer um discurso amargo e revoltado, mas não é. Só falei o que vivi nesses 12 anos que trabalho. Passei por muita coisa e passo, para poder garantir um trabalho. Acredito que as recrutadoras só terão êxito nos processos seletivos quando mudarem o ponto de vista com relação ao candidato.

Outros, como citamos acima, expressaram esta mesma ideia e complementaram, comentando que este processo está gradativamente mudando tal cenário. Em alguns casos já há muita mudança na postura das empresas em relação aos deficientes. Porém estamos em constante luta pela transformação em prol de uma sociedade mais inclusiva.

\section{Apreciação Crítica Sobre a Visão da Pessoa com Deficiência no Mercado de Trabalho}

Ao longo de toda essa pesquisa referente a tão instigante temática, percebemos que a lei 8.213/91, sem sombras de dúvidas é um essencial mecanismo que contribui cada vez mais para a inclusão da pessoa com deficiência. Estipulando, por exemplo, no seu artigo 93, o percentual destinado para essa parcela da população, quando a empresa tem em seu quadro de funcionários mais de cem empregados. Caso contrário incidirá sobre a empresa uma sanção através de multas pecuniárias. Como também, quando ocorre demissão, o empregador só poderá substituí-lo por outra pessoa nas mesmas condições, ou seja, que detenha algum tipo de deficiência. Porém não podemos deixar de comentar que em muitos casos o empregador e a lei, deixam a desejar no que se refere à inclusão. Seja em razão do empregador oferecer uma vaga para esse público, apenas para eximir-se das penalidades da lei. 
Outro fator que diminuiria o fato citado seria o detalhamento desta importante questão nesse mesmo diploma legal, no que se refere à preocupação pela verificação se as empresas apresentam instalações acessíveis para facilitar a realização das funções impostas pelo empregador.

Um aspecto de forte discussão foi a visão estereotipada que a sociedade ainda detém sobre esta parcela da população. Visão essa que não acompanhou os avanços e desenvolvimentos em vários setores da sociedade. Por isso se faz extremamente necessário que o empregador e a sociedade como um todo visualize essa minoria como indivíduos capazes de atuar na sociedade, como também importante fonte de produção e não como um fardo a ser carregado, apenas por uma imposição legal.

Essa realidade pode ser transformada se as pessoas com deficiência tiverem maior acesso à educação, que é um direito inerente à pessoa humana. Pois assim, futuramente, o mesmo terá a qualificação necessária que o mercado exige. Havendo toda essa mudança, o deficiente teria o livre acesso ao mercado de trabalho sem auxílio de diplomas legais.

Por fim, pegaremos, como base, os dados colhidos na pesquisa, por estes revelarem um pouco da prática do que apresentamos como teoria ao longo deste trabalho monográfico. O que nos chamou a atenção nas respostas no questionário, foram as dificuldades vivenciadas pelos deficientes para inserirem-se no mercado, dificultando o desempenho de seu papel social. Como vimos, as dificuldades e discriminações são muitas, mas superáveis. Não devemos parar de lutar por uma sociedade mais justa e, consequentemente, inclusiva.

\section{Considerações Finais}

Ao tratarmos de uma temática de grande relevância social que tem como centro uma busca incessante de compreensão e respeito às diferenças existentes em cada um, almejamos que a sociedade, na qual estamos inseridos, torne-se cada vez mais inclusiva e, consequentemente, mais humana. Essa transformação tem de ser efetivada de tal maneira que garanta a todos os indivíduos as mesmas possibilidades e condições para exercer, de forma digna, seu papel social, independentemente de ter ou não algum tipo de deficiência.

Porém procuramos obter um maior aprofundamento no que se refere à inclusão da pessoa com deficiência no mercado de trabalho, uma vez que, apesar dos avanços adquiridos por meio de implementação de políticas públicas, como também a elaboração de leis destinadas a atender este anseio de uma maior inclusão, destacamos a lei 8.213/91 que, embora tenha contribuído para o início desse processo, ainda não é o suficiente para enxergarmos uma inclusão plena em nesse setor.

Percebemos que, em muitos casos, ainda são frequentes situações em que o empregador admite o trabalhador que possui alguma deficiência, apenas no intuito de esquivar-se das penalidades impostas pelos diplomas legais. E não visualizando o indivíduo como um ser capaz de contribuir para 
o sucesso da sua empresa. Outro aspecto relevante é o papel fundamental que deve exercer a sociedade na desconstrução dessa visão preconceituosa, discriminatória e oportunista, que ainda paira sob essa parcela da sociedade.

O mundo moderno avançou e muito em vários aspectos. Hoje convivemos com grandes e constantes avanços nas ciências da saúde, sociais e tecnológicas. Lembremos da tecnologia assistiva, que é um importante meio que muito ajuda e facilita a vida cotidiana da pessoa com deficiência. Através desse mecanismo, tem-se amenizado as limitações oriundas dos vários tipos de deficiência. Como também é um importante subsídio para inclusão na vida social. Porém não podemos constatar grandes evoluções quando nos referimos ao aspecto humanizador no corpo social. De maneira que práticas discriminatórias e sentimentos como o preconceito ainda se encontram impregnados no seio social. Porém, são aspectos que não surgem com a modernidade, mas uma herança de tempos remotos.

Por tanto se faz necessário que tais temáticas sejam cada vez discutidas pela sociedade, ampliando seus horizontes, de maneira a transformar o mundo em que vivemos em um meio mais justo e inclusivo. E que sejam garantidas as mesmas possibilidades e condições, para que exerçamos os direitos, tais como direito a educação, saúde, lazer e ao trabalho de maneira digna e respeitosa, coibindo desta forma qualquer espécie de discriminação. Já que estes, dentre tantos outros, são inerentes a pessoa humana,

\section{Referências}

AMARAL, L. A. Conhecendo a deficiência: em companhia de Hércules. São Paulo: Robe Editorial, 1995.

BRASIL. Constituição (1988). Constituição da República Federativa do Brasil. Brasília, DF: Senado, 2014.

. Ministério do Trabalho. SIT. A Inclusão de pessoas com deficiência no mercado de trabalho. 2. ed. Brasília: MTE/SIT, 2007. Disponível em: http://portal.mte.gov.br/data/files/FF8080812CCDAEDE012CD0A2B79F70B3/inclusao_pessoas_defi 12_07.pdf Acesso em: 08 abr. 2015.

2014.

Vade Mecum: Consolidação das Leis do Trabalho - CLT. São Paulo: Revista dos Tribunais,

. Lei de Cotas nº. 8213, de 24 de Julho de 1991. São Paulo: Revista dos Tribunais, 2014.

COSTA, Fernanda Pereira. A inserção da pessoa portadora de deficiência no mercado de trabalho. Âmbito Jurídico.com.br. Disponível em: http://www.ambitojuridico.com.br/site/?n_link=revista_artigos_\%20leitura\&artigo_id=12085. Acesso em: 17 abr. 2015.

COUTINHO, Maria Luiza Pinheiro. Discriminação no trabalho: mecanismos de combate á discriminação e promoção de igualdade de oportunidades. Rio de Janeiro: Igualdade Racial, 2003. 
Disponível

http://www.oitbrasil.org.br/sites/default/files/topic/discrimination/pub/oit_igualdade_racial_05_234.pd f. Acesso em: 10 jan. 2015.

FERRAZ, Fabiana Kelly. Igualdade de oportunidades e discriminação no trabalho: uma leitura dos instrumentos legais. Rio de Janeiro: Igualdade Racial, 2003. Disponível em: http://www.oitbrasil.org.br/sites/default/files/topic/discrimination/pub/oit_igualdade_racial_04_234.pd f. Acesso em: 13 jan. 2015

LOPES, Gláucia Gomes Vergara. A Inserção do portador de deficiência no mercado de trabalho: a efetividade das leis brasileiras. São Paulo: LTR, 2005.

MADEIRO, Aymina Nathana Brandão. Bac Inclusão do Deficiente no Mercado de Trabalho de Acordo com o Artigo 93 da Lei No 8.213/. 2014

MAIA, Mauricio. Novo conceito de pessoa com deficiência e proibição do retrocesso. Disponível em:http://www.google.com.br/url?sa=t\&rct=j\&q=\&esrc=s\&source=web\&cd=1\&ved=0CB4QFjAA\& url=http\%3A\%2F\%2Fwww.agu.gov.br\%2Fpage\%2Fdownload\%2Findex\%2Fid\%2F17265873\&ei=F7 JTVfzAG6jisASlyYDYDA\&usg=AFQjCNFcXJMIROsV7VblZsSLV5x2PzbXA\&sig2=8MGNA8n4KL3dKzXuv5_DHA\&bvm=bv.93112503,d.cWc\&cad=rja. Acesso em: 24 abr. 2015

MELLO, Celso Antônio Bandeira de. O Conteúdo jurídico do princípio da igualdade. 3. ed. São Paulo: Malheiros, 2011.

MERCADO de trabalho e pessoa com deficiência: exame do artigo 93 da Lei $n^{\circ}$ 8.213/91 Trabalho. Revista: $\quad$ Âmbito $\quad$ Jurídico, $2015 . \quad$ Disponível http://www.ambitojuridico.com.br/site/?n_link=revista_artigos_leitura\&artigo_id=11955 Acesso em: 15 abr. 2015.

MIRANDA, Arlete Aparecida Bertoldo. História, deficiência e educação especial. Disponível em: http://www.histedbr.fe.unicamp.br/revista/revis/revis15/art1_15.pdf.

Acesso em: 06 jan. 2015.

ORGANIZAÇÃO INTERNACIONAL DO TRABALHO (OIT). Convenção dos Direitos da Pessoa com Deficiência; março, 2007. Disponível em:

file:///C:/Users/Melissa/Downloads/A\%20Convenção\%20sobre\%20os\%20Direitos\%20das\%20Pessoa s\%20com\%20Deficiência\%20Comentada.pdf Acesso em: 15 abr. 2015.

Normas Internacionais do trabalho sobre reabilitação profissional e emprego de pessoas portadoras de deficiência. Disponível em:

http://portal.mte.gov.br/fisca_trab/2-2-recomendacao-n-168-83-que-trata-da-reabilitacao-profissionale-do-emprego-de-pessoas-portadoras-de-deficiencia.htm

Acesso em: 15 abr. 2015.

PACHECO, Kátia Monteiro de Benedetto; ALVES, Vera Lucia Rodrigues. A história da deficiência, da marginalização à inclusão social: uma mudança de paradigma. 2007. Disponível em http://www.actafisiatrica.org.br/detalhe_artigo.asp?id=184

Acesso em: 15 abr. 2015.

PARDIM, Cleide Cardoso. O processo de inclusão da pessoa com deficiência no mundo do trabalho. Desafios e Reflexões, 2014.2 Disponível em: http://www.pedagogia.com.br/artigos/processo_inclusao_pessoa_deficiencia/

Acesso em: 15 abr. 2015. 
POLETTI, Kézia Zanni. Pessoa com deficiência e mercado de trabalho: Lei de Cotas No 8213/1991. 2010. Disponível em: http://www.apabb.org.br/admin/files/Artigos/Mercado\%20de\%20trabalho.pdf Acesso em: 15 abr. 2015

SANTOS, Andreia Tais. Inserção do portador de deficiência no mercado de trabalho. 2011. Disponível em: http://www.centropaulasouza.sp.gov.br/pos-graduacao/workshop-de-pos-graduacao-epesquisa/007-workshop-2012/workshop/trabalhos/gestneg/insercao-do-portador.pdf.

Acesso em: 15 abr. 2015.

SANTOS, Jefferson Cruz dos. Princípio da dignidade da pessoa humana na constituição cidadã.
Conteúdo
Jurídico,
Brasília,
$\mathrm{DF}$,
2011.
Disponível
em

http://www.conteudojuridico.com.br/artigo,principio-da-dignidade-da-pessoa-humana-na-constituicaocidada,33027.html.

\section{Como citar este artigo (Formato ABNT):}

DOS ANJOS, Melissa C. G.; BEZERRA, Schamkypou B.; FARIAS, Athena de A.; MARINHO, Gisanne, de O.; BARRETO, Julyanne de O.P. A pessoa com deficiência no mercado de trabalho e suas implicações. Id on Line Revista de Psicologia, Fevereiro de 2016, vol.10, n.29. p. 51- 70. ISSN 1981-1179.

Recebido: $12 / 01 / 2016$

Aceito: 26/01/2016 